\title{
Research of Solenoid Valve CDC Damper Performance Data Compression and Fusion with Active Suspension Control Strategy
}

\author{
Shuang Wang ${ }^{1, a}$, Xiaohui Bai ${ }^{2, b}$ Fang $\mathrm{Xiao}^{2, \mathrm{c}}$ and Bowei $\mathrm{Bi}^{2, \mathrm{~d}}$ \\ ${ }^{1}$ School of Automotive Engineering, Dalian University of Technology, \\ Dalian 116024, China \\ ${ }^{2}$ School of Transportation and Automotive Engineering, Key Laboratory of Sichuan Province \\ Automobile Engineering, Xihua University, Chengdu, 610039, China \\ aemail:wangshuang0702@126.com, bemail:baixh@khat.cc,

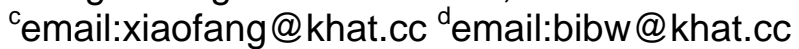

Keywords: Solenoid Valve CDC damper, Data Compression

\begin{abstract}
Solenoid Valve CDC Damper is one of mainstream commercial solutions for Active Suspension. For most of Active Suspension control strategy, CDC dampers are treated as force generator [1]. For getting desirable damper force, CDC Damper performance is necessary. There are two way to describe to CDC damper performance, data lookup and model building. Because of unpredictable extensionality, Data lookup require large of experiment data to maintain accuracy that effect efficiency of lookup algorithm. CDC damper model building involve in field of mechanism, hydrodynamics and electronic. Although model building have high quality of extensionality. But complex algorithm make it hard to implement on control unit.

I propose a new way, compressing CDC experiment data by fitting basic valve model. By understanding about construction of one type of Solenoid Valve CDC damper, I build basic damper model based on valve theory, then using experiment data to tune model parameter to fit experiment data. Basic damper model I build is simple and easy to implement on controller unit.
\end{abstract}

\section{Introduction}

There are several types of Continuous adjustable damping shock absorber, mechanical CDC Damper and MR damper. Solenoid Valve CDC damper is a kind of mechanical CDC damper. Solenoid valve CDC damper has advantage of reliability and durability. And many vehicle producer use it on active suspension or semi-active suspension. Compared with normal passive damper, Solenoid Valve CDC damper has more complex construction. So main solution of describe Solenoid Valve Damper is data lookup. For most Active (Semi-active) Suspension control strategy, CDC damper is view as force generator. By CDC V-F performance curve lookup and velocity of suspension compression get from sensor, controller unit generate certain current to drive solenoid. Then damper will generate damper force as control strategy calculate.

There are two way building damper model, physical modeling and curve fitting using neural networks. Neural works have advantage universal property, but extensionality is uncertain. So I choose physical modeling to build Solenoid Valve CDC damper. The main proposal for building model is to make CDC damper generate accuracy damping force as control strategy calculate. Even CDC model is complex, but damper force generating algorithm must be simple and easy to apply on the controller unit. For convenience, CDC damper is short for Solenoid Valve CDC damper below.

\section{Basic valve model and CDC Damper Construction Analysis}

Even construction of CDC damper is complex, but it is combined by several basic valve. So basic valve model is necessary. Circulation hole is common element of damper to generate damping force. The equation to describe hole damp performance is shown below: 


$$
Q=k \cdot \sqrt{\frac{2 \cdot p}{\rho}}
$$

The construction of damper intake valve and compensator valve is shown as Fig2. For intake valve and compression valve, damper force is generated by valve blocks. The size and numbers bring valve different performance of damping force generating. For intake valve and compression valve, the flow formula is complex and there are much research about it [6].
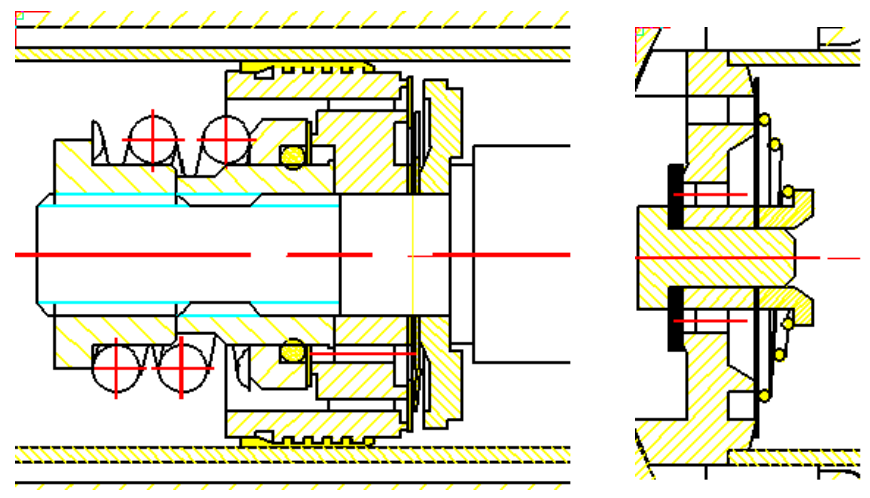

Fig.1 Construction of Intake Valve and Compensator Valve

Intake valve just consist of block valve and circulation hole. Intake valve has no spring to keep retightening load. Compensator valve consist of valve block, circulation hole and a soft disc spring. The retightening load disc spring take can be ignored. But detailed performance of intake valve and compensator valve is different. Considering CDC damper construction and relative research. The formula I choose is shown below. I choose Eq2 as intake valve flow equation and Eq3 as compensator valve flow equation.

$$
\begin{aligned}
& Q=k p \sqrt{\frac{2 \cdot p}{\rho}} \\
& Q=k p \sqrt{\frac{2}{\rho}}
\end{aligned}
$$

The last form of valve is Disc valve. There is a spring with retightening load. When pressure can't afford retightening load, the valve closed with no oil passing. When the valve open, the form of valve flow formula I choose is shown as Eq1 [5].

$$
Q=\left\{\begin{array}{c}
0 \quad p<p_{o p} \\
k\left(p-p_{o p}\right) \cdot \sqrt{\frac{2}{\rho}} \quad p \geq p_{o p}
\end{array}\right.
$$

Core element of CDC damper is CDC solenoid valve assembly. Detailed construction is shown in Fig.3, CDC solenoid valve assembly consist of one circulation hole, one disc valve and one solenoid valve. When flow is small, plunger valve is close and all [8], the form of solenoid valve flow formula is same as circulation hole. Define $\Delta p_{3}$ as pressuredrop of circulation hole. Define $\Delta p_{4}$ as pressure drop of CDC solenoid valve. Flow equation of CDC solenoid valve assembly is shown below.

$$
Q=\left\{\begin{array}{c}
k_{3} k_{4} \sqrt{\frac{2\left(\Delta p_{3}+\Delta p_{4}\right)}{\rho\left(k_{3}^{2}+k_{4}^{2}\right)}}, \Delta p_{3}+\Delta p_{4}<p_{o p} \\
k_{3} k_{4} \sqrt{\frac{2\left(\Delta p_{3}+\Delta p_{4}\right)}{\rho\left(k_{3}^{2}+k_{4}^{2}\right)}}+k_{5}\left(\Delta p_{3}+\Delta p_{4}-p_{o p}\right) \cdot \sqrt{\frac{2}{\rho}} \quad \Delta p_{3}+\Delta p_{4} \geq p_{o p}
\end{array}\right.
$$




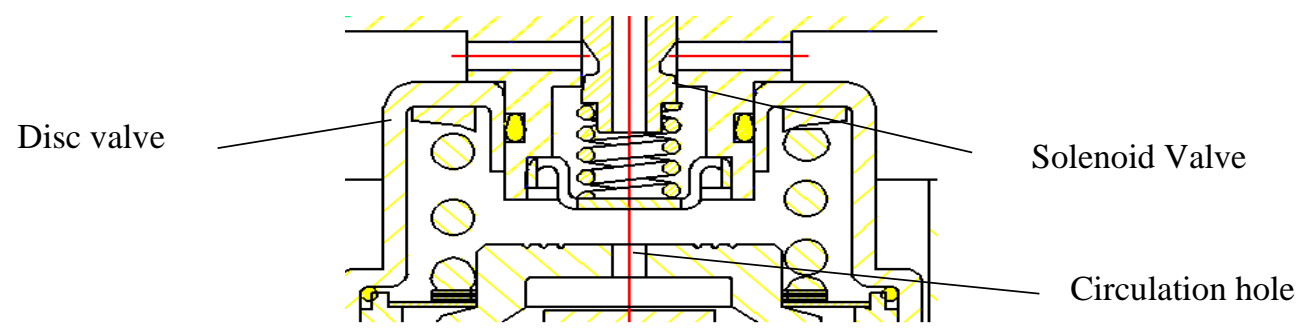

Fig 2. Construction of CDC Solenoid Valve Assembly

The construction of CDC is shown below, it is consist of inner-cavity, external-cavity, mid-cavity, intake valve, compensator valve and CDC solenoid valve assembly [3].

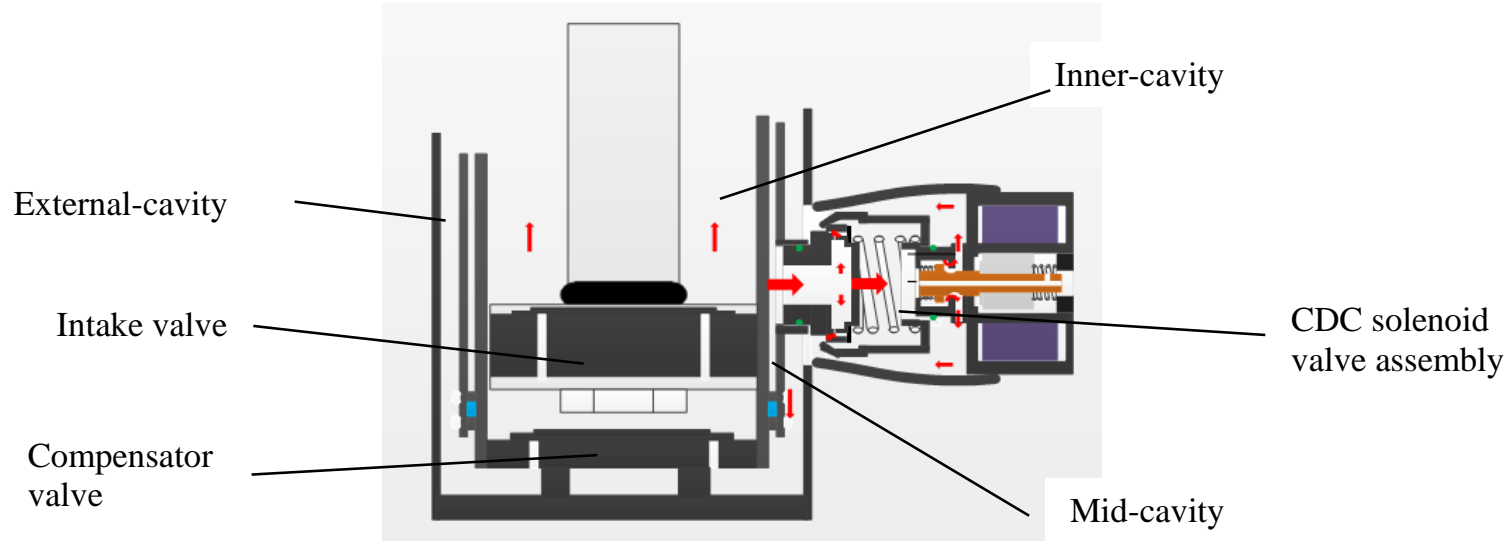

Fig 3. Construction of CDC Damper

CDC damper parameters conclude in table 1.

Table1 CDC damper parameters

\begin{tabular}{|l|c|l|l|c|c|}
\hline Valve Name & $\begin{array}{l}\text { Paramete } \\
\mathrm{r}\end{array}$ & Form of Equation & Valve Name & Parameter & Form of Equation \\
\hline Intake valve & $k_{1}$ & $Q=k_{1} \Delta p_{1} \sqrt{\frac{2 \cdot \Delta p_{1}}{\rho}}$ & Compensator valve & $k_{6}$ & $Q=k_{6} \Delta p_{6} \sqrt{\frac{2}{\rho}}$ \\
\hline Solenoid valve & $k_{3}$ & Eq. 5 & Solenoid valve & $p_{o p}$ & Eq. 5 \\
\hline Solenoid valve & $k_{4}$ & Eq. 5 & Damper gap & $k_{2}$ & $Q=k_{2} \sqrt{\frac{2 \cdot \Delta p_{2}}{\rho}}$ \\
\hline Solenoid valve & $k_{5}$ & Eq. 5 & & & \\
\hline
\end{tabular}

\section{CDC Damper Modeling and Parameter Tuning}

For control strategy, the most important performance about CDC damper is relationship of damper force and damper compress or extract velocity. And this relationship can be easy get by Shock absorber dynamometer machine.

CDC damper is complex and many parameters need to be tuned. Before this understanding how oil flow is necessary. As shown in fig 2. When damper is compressed, oil from cap-end of flow to rod-end. Then oil pass mid-cavity to CDC solenoid valve assembly. At last, oil arrive external-cavity.

When damper extract, oil in rod-end pass mid-cavity to CDC solenoid valve assembly, and arrive external-cavity. At the same time, some oil in external-cavity pass compensator valve to compensate the oil in cap-end. Fig 5 can describe oil flow. 

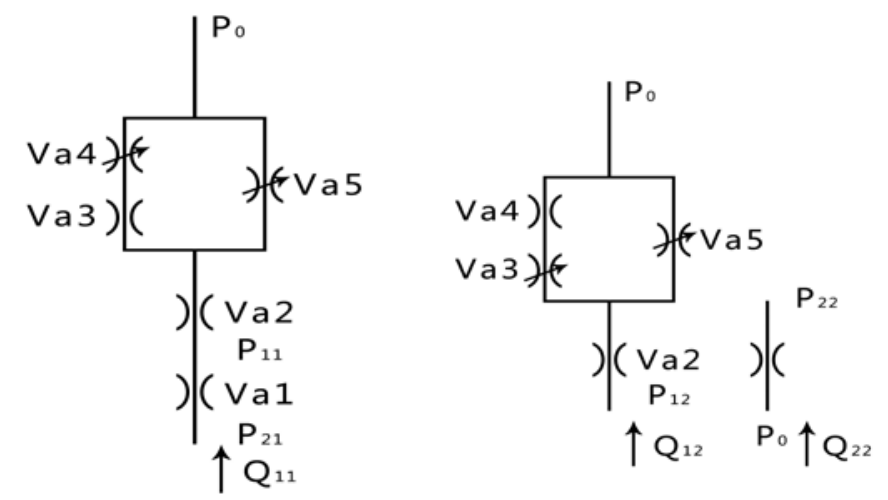

Fig 4. Fluid model of CDC Damper in Compression and Extraction Case

According to construction of CDC damper. The equation can be written below [7]: In compression case:

In extraction case:

$$
F_{\text {damp }}=\Delta p_{1} A_{\text {ring }}-\left(\Delta p_{1}+\Delta p_{2}+\Delta p_{3}+\Delta p_{4}\right) A_{\text {rod }}
$$

$$
F_{\text {damp }}=-\Delta p_{6} A_{\text {cap }}-\left(\Delta p_{2}+\Delta p_{3}+\Delta p_{4}\right) A_{\text {ring }}
$$

After getting expression about CDC compress (extract) velocity and damping force, Tuning parameter is last step for CDC damper model to fit CDC damper performance map. Genetic Algorithm (GA) is a calculation model of biological simulating natural selection that is proposed Darwin. It is a kind of method to search the optimal solution by simulating natural evolutionary process. According to relative research, GA is suitable to damper parameter tuning. I choose Dassault Isight to implement GA [4]. The fitness function is defined as Eq.8

$$
\text { fitness }=1-\frac{\sum\left(F_{\text {damper,model }}-F_{\text {damper,test }}\right)^{2}}{\sum\left(F_{\text {damper, test }}\right)^{2}}
$$

After parameter tuning, the fitness of model under different control current can be shown in Table2.

Table 2. Fitness of model under different control current

\begin{tabular}{|c|c|c|c|}
\hline Control current & fitness & Control current & fitness \\
\hline 0A & $98.3 \%$ & $3 \mathrm{~A}$ & $95.7 \%$ \\
\hline 1.5A & $97.6 \%$ & $4.5 \mathrm{~A}$ & $93.2 \%$ \\
\hline
\end{tabular}

\section{ECU implement}

This is simple to design damping force generating algorithm, if you get the value of parameter the Table 1. Include. For most semi active suspension control system suspension deform can get from sensor directly. Differ suspension deform signal, suspension deform velocity get. Then I can get flow pass each valve. After control unit calculate desirable damping force. According to Eq. 1-7 and Table 1. Parameter $k_{4}$ get, depending on relationship $k_{4}$ and control current, I can get control current.

\section{Summary}

The CDC damper model can describe CDC damper performance under different control current. Although the model is complex, but for suspension control unit, Suspension deform velocity and 
desirable damping force is available [2]. Calculating CDC damper control current is simple. Compared with data lookup, modeling damping force calculation cost less ROM.

\section{References}

[1] XueMei Sun, Yaxu Chu, Jiuchen Fan, Qiuxiao Yang: Research of Simulation on the Effect of Suspension Damping on Vehicle Ride Energy Proscenia. 2012

[2] Jeong-Hoon Kim, Chong-Won Lee: Semi-active damping control of suspension systems for specified operational response mode, Journal of Sound and Vibration 2011-2

[3] Information on http://www.zf.com/

[4] H. Metered,P, Bonello,S.O.Oyadiji: The experimental identification of magnetorheological dampers and evaluation of their controllers[J]. Mechanical Systems and Signal Processing. 2009 (4)

[5]Alexander Lion, Swenja Loose.A: thermo-mechanically coupled model for automotive shock absorbers theory, experiment and vehicle simulations. Journal of Vehicle System Dynamics. 2002

[6] Wallaschek: Dynamics of Non-line Automobile Shock Absorbers. International Journal of Non Linear Mechanics. 1995

[7]S. Emmons, C. Boggs, M. Ahmadian: Parametric modeling of a highly-adjustable race damper. ASME International Mechanical Engineering Congress and Exposition . 2006

[8]C. Boggs, M. Ahmadian, S. Southward:Efficient empirical modelling of a high-performance shock absorber for vehicle dynamics studies. Veh. Syst. Dyn . 2010 